\title{
«La palabra naciente»: María Zambrano y la razón patriarcal
}

\author{
«La palabra naciente»: María Zambrano \\ and Patriarchal Reason
}

\author{
Carmen Velasco Rengel \\ Universidad de Málaga \\ carvelasco@uma.es \\ ORCID iD: http://orcid.org/0000-0002-2053-5390
}

\section{RESUMEN}

El propósito de este ensayo es confirmar y revalidar la vigencia de la obra literaria de María Zambrano. Al mismo tiempo, se analiza la influencia del punto de vista femenino de la autora en su creación, destacando como paradigma de esta el tratamiento que ha dado a la figura clásica de Antígona en su obra La tumba de Antígona. La «vida no vivida» representada por Antígona sirve a Zambrano para reabrir una puerta que había quedado sellada tras el cruel final de la tragedia de Sófocles. De este modo, la autora acertaría a reescribir el perfil de la heroína trágica, confiriéndole una dimensión subversiva en relación con la historia del pensamiento patriarcal. Por último, se estudia cómo María Zambrano en esta obra abandona el género del ensayo y se adentra en la ficción dramática, pues necesita el lenguaje literario («la razón poética») para expresar su pensamiento con más fuerza.

Palabras Clave: Antígona; Zambrano; Sófocles; mito; patriarcado; lenguaje literario; intertextualidad.

\begin{abstract}
The purpose of this essay is to confirm and revalidate the relevance of Maria Zambrano's literary work. At the same time, it analyses the influence of the feminine point of view in her creation. To reach this goal, it is necessary to underline as a paradigm the treatment that she has given to Antigone's figure. Thus, Zambrano reopens a door that had remained sealed with the cruel end of Sophocles Tragedy. Also, she redefines this tragic female figure, giving a subversive dimension to her in connection with the history of the patriarchal thought. Likewise, it points to the fact that Zambrano leaves the essay to approach in literary fiction, because she needs literary language, «the poetical reason», to express his thinking.
\end{abstract}

Key words: Antigone; Zambrano; Sophocles; Myth; Patriarchy; Literary language; Intertextuality. 
1. EN LOS OJOS DEL PADRE

El cínico se retira de la ciudad quedándose en ella para ver sin reparar en su mirada. Y para ello, según la leyenda, busca ayuda de una mayor luz. Es la luz de la visión la que busca, la luz que delata y que puede ser dirigida a voluntad, la luz de la linterna, ojos sin pasión alguna. Ironía delatora de esta linterna esclarecedora de la oscuridad.

(Moreno Sanz 2004: 28)

La obra entera de María Zambrano «es un desafío a las estructuras masculinas de la cultura occidental», como ha señalado la filósofa Wanda Tommasi (2002: 209). Zambrano es una figura principal de un valor insoslayable, entre otras muchas cosas, porque rescata para la filosofía una visión diferente, una «razón de amor» donde se admite la piedad al mismo tiempo que la ironía. Esta sensibilidad distinta es una actitud vinculada sin duda a su feminidad, al hecho de que era una mujer. Pues esta inmensa personalidad del pensamiento español propone un reto fundamental: en su obra hay lugar para la vida, para la carne, al mismo tiempo que para la palabra, para la sabiduría. No podemos olvidar que en los pactos patriarcales sustentados por nuestra sociedad y por la historia de la filosofía no habría espacio para el conflicto que se produce entre la cabeza y el cuerpo; esto es, no ha habido hasta hace poco interés por diseñar una cartografía de un nuevo espacio para pensar. Inamovible a lo largo de siglos de pensamiento, la mujer permanece en el imaginario colectivo como naturaleza, como cuerpo; por el contrario, el hombre es la cabeza. Este es el discurso universal que ha pretendido la filosofía. De ahí el desafío que supuso para una mujer nacida a comienzos del siglo veinte ser filósofa. En este artículo pretendemos poner en valor este aspecto de tan meritoria obra y de la personalidad de la filósofa andaluza.

Ambos conceptos, como decimos, se contradicen en los términos: la filosofía y la historia de la filosofía llevan implícitas la primacía del varón y la sabiduría patriarcal (Amorós 1985: 27); por tanto, lo que la mujer representa no forma parte de ellas. A lo largo de la historia de la humanidad, en el caso del género femenino, no se han anudado vida y palabra. La vida que procuraba la mujer no comportaba reconocimiento jurídico, no llevaba certificado de legitimidad; era solo nuda vida o vida nutricia (si recordamos a Aristóteles), como indica Agamben (1998: 152); por consiguiente, vida como naturaleza, vida biológica. Por tanto, no era vida según el logos, según el Verbo, como establece el Evangelio de San Juan: «En el principio era el Verbo». El logos, la palabra, el razonamiento no formaban parte del legado que ha recibido la mujer desde el comienzo del pensamiento patriarcal. Por el contrario, habría que aseverar, utilizando nociones lacanianas, que el falo ha sido el significante 
privilegiado; o tomando ideas del filósofo Derrida (1986: 20), que la batalla del pensamiento ha utilizado en su larga historia una clara estratagema falogocéntrica.

Sin embargo, con la pasión propia de las exploradoras de lo desconocido, de las pioneras que movilizaron y forjaron un nuevo tipo de conocimiento, incluso a pesar de que su padre fue quien la enseñó a mirar y, por ende, a pensar el mundo - circunstancia definitiva para el pensamiento, como ella misma cuenta en sus escritos-Zambrano afronta la racionalidad clásica que sustenta la filosofía y da una respuesta contundente, que desmonta el andamiaje patriarcal mediante la mítica figura de Antígona.

En este camino encontramos dos aspectos que han predominado a lo largo de la andadura creadora de la filósofa; por un lado, las sombras de las grandes influencias, grandes figuras patriarcales como Heidegger, Zubiri y Ortega y Gasset (Zambrano 2006: 42); por otro lado, la reconfiguración de sus planes vitales, rotos por Ortega, quien manifestara cierto menosprecio ante su intento de conjugar poesía y filosofía (Sánchez Villaseñor 2007: 58). Huyendo de esta aporía que sometía un pensamiento dispuesto a despegar, definió una nueva fase fundamental en su vida con un enunciado que ella pensaba podría servir a las mujeres: «Al no haber podido morir, sentía que tenía que nacer por sí misma» (Valls Llobet 2006: 131). Para Zambrano, en un momento determinado de su vida — que incluía la superación de una enfermedad— había llegado el momento de renacer y buscó inspiración en Antígona, el personaje trágico que ya había sido los ojos de su padre Edipo. De este modo, como ha hecho notar Virginia Trueba en su prólogo a La tumba de Antígona y otros textos sobre el personaje trágico (Zambrano 1967: 13): «Antígona acompaña a Zambrano a lo largo de su trayectoria como escritora»; por lo que, salvando al personaje de la muerte, va afirmando y esclareciendo su propio pensamiento.

Hay una foto muy conocida que muestra uno de los momentos intelectuales significativos vividos por María Zambrano, donde se evidencia el ambiente masculino de la época en la que se formó su propio «yo» ante la filosofía. Es una imagen que nos habla sin palabras y manifiesta aspectos definitivos de su figura singular. El escenario de la toma es el Aula Magna de la Universidad de La Habana, en 1943, durante la inauguración de la «Reunión de profesores españoles en el exilio». Zambrano está sentada en primera fila, rodeada de grandes hombres, grandes figuras como ella misma. A su izquierda, Fernando de los Ríos, a su derecha Joaquín Xirau. Sin embargo, su imagen destaca entre los demás asistentes al acto, hipnotiza, atrapa a causa de su gesto: ellos miran hacia arriba o al frente, ella tiene la mirada baja. La advertimos recogida, como si su rostro estuviera replegado hacia el interior, con las manos entrelazadas en el regazo. La suponemos solitaria, no aislada, con una especie de fuerza oculta, concentrada en algo que trabaja por debajo; y también, en cierto modo, «sola ante el peligro», despojada, pues al fin y al cabo el exilio se la llevó a Cuba, México, Nueva York, Francia e Italia. 
Intentamos comprender ese gesto abstraído, entender qué piensa en ese momento, y nos damos cuenta de que estamos siendo testigos privilegiados de su actividad filosófica que consiste en «bajar la mirada» para atender incluso a lo insignificante, en «bajar las palabras demasiado llenas de sí mismas» (Revilla Guzmán 2005: 220). En ese gesto de humildad advertimos toda una sabiduría que traspasa los límites de lo establecido por los patriarcas del pensamiento. Es un gesto que parece esperar una idea, la gestación del pensamiento; puesto que, como ella misma escribió a Agustín Andreu en sus Cartas de la Pièce: «El pensamiento que se da a la luz ha de ser concebido y eso es doloroso y algo más, algo inenarrable: desgarramiento, entrega, oscura gestación, luz que enciende en la oscuridad hasta que la claridad del Verbo aparece» (Zambrano 2002: 249).

Así pues, ese gesto tiene que ver con el lado femenino de Zambrano que va sustancialmente relacionado con su pensamiento. Al mismo tiempo, en esa foto se encuentra también la mujer llena de valentía, una mujer que se transforma, que muta: en esa imagen está latiendo su devenir Antígona, que busca lo no-dicho, lo silenciado, rebelándose contra la doble «cárcel del lenguaje» a la que está sometida, y dominando a su vez a un sistema filosófico que es paradigma del pensamiento patriarcal. Hablando de lenguaje, nos remitimos a las definiciones de diferentes vocablos y recordamos que el término «filosofía»; en la vigesimotercera edición del Diccionario de la lengua española de la RAE es definido de la siguiente forma: "Conjunto de saberes que busca establecer, de manera racional, los principios más generales que organizan y orientan el conocimiento de la realidad, así como el sentido del obrar humano». Asimismo, «filósofo, fa» significa «que afecta lenguaje y modos de filósofo», o bien la «persona virtuosa y austera que vive retirada y huye de las distracciones y de los lugares muy concurridos $\rangle^{1}$. De este modo, podemos acordar que la tarea de «filosofar» — como indica una de las acepciones del DRAE en su 23. a edición«examinar algo como filósofo, o discurrir acerca de ello con razones filosóficas», estaría relacionada con ese gesto (tan femenino por otra parte) de Zambrano y podría tener que ver, paradójicamente, con su «empoderamiento» como mujer filósofa, con su singularidad y con el modo en que se produce el pensamiento desde la feminidad; esto es, como alumbramiento, poiesis, «razón poética».

En septiembre de 1956, en Diotima. Fragmentos (Zambrano 2014: 403), escribe lo siguiente:

Me fui convirtiendo en oído y al volver nadie me escucha; me adentré en el silencio y soy su prisionera y aunque hubiera aprendido a escribir no podría hacerlo. Creí que el escribir es cosa de unos pocos hombres, el hablar en cambio me

\footnotetext{
1 Aplaudimos a la RAE por los cambios introducidos en esta última edición, que corrige las anteriores ediciones, más sesgadas en cuanto a la utilización del género femenino.
} 
era natural y como todas las cosas que se hacen según la naturaleza, tenía sus interrupciones, sus eclipses. La palabra misma es discontinua.

En este ir y venir del escuchar al hablar, del oído al lenguaje, se mueve el pensamiento de Zambrano, su «razón poética», que tiene que ver con la voz, con la música de la voz y con la crítica a la razón patriarcal; en definitiva, con la ideologización del discurso del patriarcado.

En este sentido, el espléndido retrato que hizo E. M. Cioran de la filósofa en el capítulo «Una presencia decisiva» (1992: 178-179) de Ejercicio de admiración y otros textos, facilita ciertas claves fundamentales sobre esta pensadora:

María Zambrano forma parte de esos seres que lamentamos ver demasiado poco, pero en los cuáles no dejamos de pensar y que quisiéramos comprender o por lo menos adivinar. Un fuego interior que se oculta, un ardor que se disimula bajo una resignación irónica: todo en María Zambrano desemboca en otra cosa, todo implica un matiz de más allá, todo.

Por mucho que uno pueda hablar con ella de cualquier cosa, se tiene, sin embargo, la certeza de que antes o después nos deslizaremos hacia interrogantes esenciales sin seguir necesariamente los meandros del razonamiento. De ahí un estilo de conversación en nada entorpecido por la tara de la objetividad y gracias al cual ella nos conduce hacia nosotros mismos, hacia nuestras perplejidades virtuales. Recuerdo con precisión el momento en que, en el Café de Flora, tomé la decisión de explorar la Utopía. Sobre este tema, que habíamos tocado de pasada, citó ella una opinión de Ortega que comentó con insistencia; yo resolví en ese mismo instante entrar a fondo en la nostalgia o en la espera de la Edad de Oro. Tal hice luego con una curiosidad frenética que, poco a poco, había de agotarse o transformarse más bien en exasperación. Lo cierto es que dos o tres años de extensas lecturas tuvieron su origen en aquella conversación.

Pues como se puede apreciar en las palabras del escritor de origen rumano, el conocimiento personal importa mucho a la hora de comprender a cualquier escritora o escritor, es una base importante para la interpretación de un pensamiento que se constituye de modo «rizomático», por decirlo con palabras de Deleuze y Guattari (1994: 15). Siguiendo con el «ejercicio de admiración» de Cioran (1991: 180) hacia la filósofa española, reproducimos otras palabras reveladoras:

Desde el momento en que una mujer se consagra a la filosofía, se vuelve presuntuosa y agresiva, y reacciona como una extraña. Arrogante y sin embargo insegura, visiblemente exiliada, no se encuentra, a todas luces, en su elemento. ¿Cómo es posible que el malestar que inspiraría no se experimente nunca en presencia de María Zambrano? Con frecuencia me lo he preguntado y creo poseer una respuesta: María Zambrano no ha vendido su alma a la Idea, ha protegido su esencia única colocando la experiencia de lo Insoluble por encima de la reflexión sobre él, ha dado en suma un paso más allá de la filosofía... Para ella, nada es verdad salvo lo que precede o lo que sigue a lo formulado, únicamente el verbo que se 
hurta a las trabas de la expresión o, como ella misma ha dicho magníficamente, «la palabra liberada del lenguaje»².

Con todo, entre las aportaciones que nos ha dejado Zambrano, destacamos expresiones como «la palabra liberada del lenguaje», «la razón en la sombra», «el pensar vivificante» o «el pensar entre lo sagrado y lo divino», que son nociones de su pensamiento crítico y además permiten sintetizarlo; referencias que pertenecen ya a la tradición filosófica española, aportaciones imprescindibles para profundizar en lo humano: «La palabra, yo quisiera... la palabra naciente» (Zambrano 2014: 621). En puridad, el pensamiento zambraniano trataría tanto de volver a pensar lo enterrado por la filosofía (la vida), como de rescatar la poesía.

\section{ANTÍGONA: LA LITURGIA DE LA TRADICIÓN}

La filosofía no siempre ha olvidado el origen, sino que partiendo de él ha salido a rescatar el ser perdido de las cosas, para forjar su unidad.

(Zambrano 2015:768)

María Zambrano habla para reconciliarnos con el pasado, que es el presente y el futuro, y Antígona es la voz con la que se comunica con nosotros. Sus palabras son un intento de resumir los principales temas zambranianos, además de actualizar el personaje griego y traerlo al presente, a esta «vida líquida», a esta era de «modernidad líquida» (Bauman 2004) donde «la idea de una vida sin mito es en sí un mito» (Gray 2013: 98). A causa de esto, a lo largo de los años considerables pensadores y pensadoras se han acercado al mito y este sigue sirviendo para adentrarse en la feminidad y conocerla mejor.

Hay muchas interpretaciones de este personaje femenino. En él se combinan con especial vigor dos ideas: por un lado, su relación con la naturaleza; por otro lado, su papel de mediadora. Antígona representa la ley divina y Creonte la ley humana: la ley es por excelencia la Ley del Padre, la Metáfora Paterna, un significante fálico, la razón patriarcal: «Pero mientras yo viva no gobernará una mujer», exclama Creonte en la tragedia Antígona de Sófocles (v. 526). A

2 Añadimos estas otras palabras de Cioran de la misma obra, igualmente esclarecedoras: "¿Quién como María Zambrano, yendo al encuentro de nuestras inquietudes, de nuestras búsquedas, posee el don de dejar caer el vocablo imprevisible y decisivo, la respuesta de prolongaciones sutiles? De ahí que quisiéramos consultarla en los momentos cruciales de una vida, en el umbral de una conversión, de una ruptura, de una traición, en la hora de las últimas confidencias, graves y comprometedoras, para que nos revele y explique a nosotros mismos, para que nos reconcilie tanto con nuestras impurezas como con nuestros callejones sin salida y nuestros estupores». 
pesar de todo, Antígona, desafiando la ley de Creonte (humana, por tanto), enterrará a su hermano.

Como es sabido, el crimen de Antígona fue sepultar a su hermano después de que Creonte, su tío y rey, hiciera público un decreto prohibiendo su entierro. Su hermano, Polinices, encabeza el ejército enemigo contra el régimen de su propio hermano en Tebas con el fin de conseguir lo que considera su lugar legítimo como heredero del reino. Ambos, Polinices y su hermano Eteocles, murieron. Poco después, Creonte, tío por parte materna de los hermanos fallecidos, al considerar que Polinices había sido infiel, le niega un funeral apropiado e incluso pretende exponer su cuerpo desnudo, deshonrado y saqueado. Antígona actúa. Ella se ve obligada a enterrar a su hermano dos veces. La segunda vez los guardias denuncian haberla visto. Cuando la heroína comparece ante Creonte, actúa otra vez, ahora utilizando la palabra, rehusando negar su implicación directa en el acto.

Existen muchas interpretaciones de la tragedia clásica y de la hija de Edipo, algunas podrían verse afectadas por la ceguera del mismo Tiresias, quien vivió la experiencia de ser hombre y mujer, además de vaticinar grandes males ${ }^{3}$. Por ende, el personaje y el mundo trágico griego suponen una gran ocasión para representar un nuevo campo de lo humano, cuando el menos que humano habla como humano, cuando el género es desplazado y el parentesco se hunde en sus propias leyes fundadoras.

La primera interpretación de Antígona la proporcionó Hegel en su Fenomenología del Espíritu (1807, en los dos títulos de la primera parte) que acaso sea la que todavía prevalece en el discurso filosófico. En ella, Antígona representa el parentesco y su disolución, y Creonte un orden ético y una autoridad estatal emergentes basados en principios de universalidad. Hegel la identifica con una transición de la norma del matriarcado a la del patriarcado, aunque también con el principio del parentesco. Para el filósofo alemán, sería lo que se encuentra más próximo a la naturaleza dentro del ámbito de la cultura.

Como ha apuntado Steiner en su obra fundamental dedicada al personaje de Antígona, Kierkegaard situaría en el centro del mito griego la relación de Antígona con su padre Edipo y el conflicto del deber fraternal de dar sepultu-

${ }^{3}$ Recordemos la historia de Tiresias, ese hombre que se convierte en mujer después de separar a dos serpientes a las que sorprende apareándose. Siete años más tarde, Tiresias volvió a ver a las mismas serpientes en las mismas circunstancias, volvió a golpearlas con su bastón para separarlas y, al hacerlo, se convirtió nuevamente en varón. Esta experiencia única hizo que Zeus y Hera recurrieran a él como árbitro en una discusión sobre quién experimentaba más placer sexual, si los hombres o las mujeres. Cuando afirmó que el hombre experimenta una décima parte del placer que la mujer, Hera, indignada, lo castigó dejándolo ciego. Zeus, sin embargo, le otorgó el don de la profecía y una larga vida. El significado esencial de la figura de Tiresias reside en su papel de mediador, gracias a sus dotes proféticas, media entre los dioses y los hombres; por su condición andrógina, lo hace entre hombres y mujeres; y por la excepcional duración de su vida, entre los vivos y los muertos. 
ra a su hermano muerto en lugar de la relación entre los hermanos, así como la obediencia a las leyes cívicas, encarnada en el poder político, del modo en que lo hiciera Hegel. En Kierkegaard no aparece lo que se podría denominar el lado político del conflicto. El filósofo danés supone la figura de Antígona como catalizadora de los fantasmas del incesto e incluso la inviste de los aspectos míticos del andrógino. La vida de Antígona sería «a secret painful unto death» (Steiner 1984: 60), como si fuera depositaria de un profundo secreto. Heidegger igualmente menciona la relación entre la Antígona de Sófocles y el pensamiento de Parménides, mientras su propio pensamiento se establece en el diálogo con un poeta como Friedrich Hölderlin (Steiner 1984: 174).

Dado que el lenguaje contiene una violencia que lo lleva a los límites de lo pronunciable, de lo decible, Freud tiene mucho que decir de la tragedia griega y de un personaje como Antígona. Según el padre del psicoanálisis, lo melancólico indica un «lamento» que apuntaría a una reclamación jurídica donde el lenguaje se convierte en el acontecimiento de la pena que surge de lo impronunciable «[...] se trata de un saber que viene después de la radical maravilla de conocer» (Steiner 2013:145). A pesar de esta afirmación, que se relacionaría directamente con la idea zambraniana de «delirio» — y de que Zambrano tuviera en cuenta a Freud hasta el punto de escribir un artículo titulado «El freudismo, testimonio del hombre actual», en 1939, donde analiza la obra del autor y la trascendencia del hombre contemporáneo- ella no consideraba demasiado cercano al pensador austriaco. Por el contrario, la filósofa se sentía mucho más próxima a Jung por su concepto del arquetipo. Ahora bien, no habría que olvidar que Zambrano conocía (al menos parcialmente) la obra de Freud y le reconocía su valentía de hombre de ciencia, como apunta María Luisa Maillard (1997: 93).

Dentro de la teoría psicoanalítica contemporánea, basada en los trabajos de Jacques Lacan, la relación con el psiquiatra francés se interpreta de un modo aún más dispar. En su VII Seminario, Lacan ofrece una interpretación de Antígona que la sitúa en los límites de lo imaginario y lo simbólico (Rabinovich 1995: 88).

Después de María Zambrano, la figura de Antígona ha sido objeto de intenso debate por parte de algunas de las pensadoras más destacadas del feminismo. Encontramos una defensa de Antígona en una de las mayores exponentes del movimiento filosófico feminista europeo contemporáneo, Luce Irigaray. Para ella, Antígona significa la transición de una norma legal, basada en la maternidad y en el parentesco, a una norma legal basada en la paternidad; como cita Judith Butler (2001: 16), aunque dude de la función representativa de Antígona. En efecto, Butler, experta tanto en los estudios de las mujeres como en las transformaciones sociales, se pregunta en su libro El grito de Antígona lo diferente que hubiera sido el psicoanálisis si hubiese tomado como punto de partida la figura de Antígona en lugar de la de Edipo (Butler 2001: 18). 
... siempre vale la pena reflexionar sobre su ejemplo como figura histórica y como identidad e identificación para muchas niñas y mujeres de hoy. Luce lrigaray y otras ensayistas la han interpretado: no como una figura política con un discurso desafiante de implicaciones políticas, sino como alguien que articula una oposición prepolítica a la política, representando el parentesco como la esfera que condiciona la posibilidad de una política sin tener que participar nunca en ella.

Por último, el filósofo Slavoj Žižek (2004: 64), lanza la hipótesis de que «el acto como real es "femenino" en contraste con lo performativo "masculino"»; es decir, el gran gesto fundador de un nuevo orden sería femenino. Más adelante veremos en qué consistiría ese gesto concedido a Antígona por María Zambrano.

\title{
3. Vigilar A LOS Vigilantes
}

\begin{abstract}
¿Nacer es un sacrificio a la luz? Y por eso Edipo se arrancó los ojos por haber vuelto al lugar del nacimiento, en vez de seguir naciendo, aceptando el sacrificio de sentirse cada vez más hundido en las tinieblas, a medida que se ve más y con mayor claridad.
\end{abstract}

(Zambrano 2014: 850)

Hay dos obras fundamentales que María Zambrano dedica a Antígona, obras límite para un personaje límite. Una de ellas es El delirio de Antígona, otra La tumba de Antígona.

El delirio de Antígona se edita en 1948 (cuando ella estaba en París), aparece en la revista cubana Orígenes y es el primer «delirio» que publica Zambrano. Para entonces ya está conformada la especial epistemología que implican los «delirios». Vinculado a la «razón poética», el «delirio» es un modo de «decir» la experiencia (histórica o metafísica) de los límites, dar forma a aquello que ha permanecido oculto o ignorado. En la obra de María Zambrano, el delirio deviene lenguaje nacido del más hondo sentir ante el abismo de la existencia. Es un grito primordial que al articularse encuentra el sentido, pues de este modo lo universal se concreta.

Como hemos dicho, El deliro de Antígona es el primer «delirio» que publica la autora, luego llegarán otros: Tres delirios (1954) Diotima de Mantinea (1956), Delirio, esperanza y razón (1959); y los «delirios» de la segunda parte de Delirio y destino. Todos ellos se han recogido en el volumen Obras completas VI, junto con los Escritos autobiográficos, Poemas (1928-1990) y su novela Delirio y destino. Los veinte años de una española (1952). En este primer «delirio», la palabra de Antígona está dirigida a un interlocutor masculino ausente: es rey, novio, marido, hombre, varón, hermano y padre. Las nu- 
merosas preguntas que nadie responde actúan como un mecanismo estructural que proporciona al texto un ritmo de letanía y de tiempo detenido. La fuerza de las imágenes como las entrañas, la larva o la mariposa actúan a veces como metáforas o símbolos: «la mirada como cuchillo», «la mujer henchida como una nave» y otras muchas. En la obra, el cuerpo de Antígona se convierte en estatua y así desaparece su feminidad (Zambrano 2014: 304):

Mi sangre descendió y fui también una flor y un cordero... Y me parecía que no tenía cuerpo, que me hundía en un frío sin nombre y me encogí. ¡Qué pálida cenicienta fea, sí fea debí de estar en ese instante, porque tuviste miedo - ¿ ¿Te has puesto enferma?"- y hubiera huido si mis pies no se hubieran hundido en la tierra.

La obra consiste en un monólogo, como un gemido de la heroína, que se ve interrumpido en un momento por un personaje ambiguo masculino del que sabemos que viene de un tiempo anterior. Discurso y cuerpo son un todo y ambos se concentran aquí en sus propias entrañas, origen del sentir; el cuerpo por nacer al final del texto se cubrirá de cabellos grises y vestidos desgarrados.

Este largo discurso de Antígona consigue transmitir la desolación femenina más profunda; el lamento de un cuerpo sin conciencia de sí, la fertilidad ahogada por el destino. Al final invoca e interroga (Zambrano 2014: 305) al «hombre, varón, hermano-novio desconocido, ¿por qué no apareciste?... Soy vuestra víctima. Sola, sola está aquí vuestra caña, vuestra alondra, pobre paloma perdida. ¿Qué hacéis?».

Así pues, de una obra a otra, el personaje cambia, «es en el tiempo», por decirlo con palabras de Zambrano. De ese grito primordial que se produce en El delirio, una desesperación más emotiva, el personaje pasa a formular un potente discurso en otra obra. En efecto, hay que esperar a La tumba de Antígona y en concreto, al último monólogo del personaje, para encontrar a una Antígona «empoderada» avant la lettre, nacida de lo más profundo de la entraña, de la tumba que habita, y su renacimiento como un Jesucristo femenino.

La tumba de Antígona aparece en su versión impresa en 1967 y el gran interés que tiene, entre muchos otros, es que Zambrano decida hablar de tú a tú con Sófocles desde la literatura. La filósofa abandona el ensayo y se adentra en la ficción dramática, necesita el lenguaje literario, «la razón poética», para expresarse, para decir al tiempo que «su» Diotima (Zambrano 2014: 648): «La revelación que llega y que separa dejando la sombra inverosímil y la ausencia incierta, ella, la verdad es así»». La obra está compuesta por doce escenas breves con títulos. Los personajes descienden para hacerla salir de la tumba; sin embargo, la heroína nunca lo hará. Pues como registra la propia Antígona en la escena titulada «La noche» (Zambrano 1967: 179): «Porque no escuchan, los hombres. A ellos, lo que menos les gusta hacer es eso: escuchar». Ya al final de La tumba, en la duodécima escena, titulada «Los desconocidos», el perso- 
naje denominado Desconocido Segundo en cierto modo le responde dirigiéndose al otro desconocido, refiriéndose a Antígona ante su negativa a salir de la tumba (Zambrano 1967: 236): «Mientras haya hombres hablará sin descanso, como la ves ahora, en el confín de la vida con la muerte. ¿Has entendido?»

En otros términos, La tumba de Antígona es un ejercicio soberano de intertextualidad. María Zambrano hace hablar al personaje justo donde termina la tragedia de Sófocles. Al hacer vivir su propia muerte a Antígona, en una dimensión que puede ser a la vez sueño y visión, acaba naciendo. Por lo tanto, la Antígona zambraniana no muere, sino que nace; o mejor, renace.

Volvamos a la tragedia de Sófocles, en ella se nos cuenta que Antígona se ahorcó en su cámara mortuoria. Ni qué decir tiene que Zambrano no acepta tal final para su personaje; para ella, es inadmisible admitir ese fin y su respuesta es El delirio de Antígona. Vemos cómo, también en su prólogo al mencionado Delirio, Zambrano niega rotundamente este final, equiparando esa negativa con el «no» rotundo al poder estatal que lanza Antígona a Creonte, en un acto paradigmático de lo «femenino», como si ambas (heroína y persona) se excluyeran, una de la comunidad y otra del texto canónico.

«Lo que se ha roto ya no puede ser pegado» (Bauman 2004: 27), esta sería una de las conclusiones de este ensayo y, en este sentido, esa rotura es que la versión más revolucionaria, más contraria a la razón patriarcal que se ha dado hasta ahora del personaje de Antígona, la ha proporcionado María Zambrano. Sin duda, ella ha puesto al mismo nivel la figura de una mujer y la de Jesucristo; mas no del modo en que lo hizo la María Magdalena del evangelio apócrifo de Pedro, donde María Magdalena se presenta como una discípula de Jesucristo que hace en el sepulcro lo que suele hacer una mujer por sus muertos (Schaberg 2002: 55): Antígona es quien «está» en el sepulcro en la obra de Zambrano. Recordemos que en el Evangelio de Tomás hay dos menciones peculiares a María Magdalena. La segunda forma parte de un pasaje enigmático y controvertido que consideramos ilustrativo (Santos Otero 1985: 707):

Simón Pedro les dijo: “iQue se aleje María Magdalena de nosotros!, pues las mujeres no son dignas de la vida". Dijo Jesús: "Mira, yo me encargaré de hacerla macho, de manera que también ella se convierta en un espíritu viviente, idéntico a vosotros los hombres: pues toda mujer que se haga varón, entrará en el reino del cielo".

Según este texto, el gran gesto fundador solo se establecería por medio de Jesús, quien, en último caso, tendría el poder de cambiar el sexo (convertirlo siempre en masculino) para cualquiera que quisiera ser acogido en su reino. El acto simbólico tendría lugar de este modo únicamente mediante la «acción patriarcal». Para subvertir este mecanismo excluyente, Zambrano niega el suicidio de Antígona, la encierra en su cámara mortuoria en vida, por voluntad 
propia, y le da la palabra, el verbo, el logos. En su prólogo a El Delirio de Antígona (Zambrano 2014: 299-300) leemos lo siguiente:

¿Cómo podría ella la que no tuvo tiempo de descubrirse ni de ser descubierta, ejecutar esa acción...? Hubo de entregarse al delirio... Ella no había venido a «vivir su vida», sino a ofrecerla sellada en su vaso: pues el cuerpo virgen de Antígona es el vaso que en todos los sacrificios aparece.

De este modo, Zambrano transforma a Antígona en un redentor femenino. He aquí lo que se podría denominar la «eucaristía de Antígona», es la consagración que renueva el sacrificio de Jesucristo. En este caso, no sería en la cruz sino en la tumba; no es el hijo de Dios, sino una hija producto del incesto, una mujer: Antígona, quien al final es ofrecida como carne y sangre.

Si ahondamos en la importancia del prólogo y del Delirio de Antígona, del que se han dado tantas interpretaciones, advertimos que Zambrano presenta a Antígona como una figura paralela a la de Jesucristo: la propia Antígona, es la hija de Dios. En este sentido, el punto de vista doctrinario que aporta la pensadora tendría relación con una tentativa de feminización del mundo: «No; Antígona, la piadosa, nada sabía de sí misma, ni siquiera que podía matarse [...] tenía que entrar en una larga galería de gemidos y ser presa de innumerables delirios; su alma tenía que revelarse y rebelarse» (Zambrano 2014: 298).

Para ir concluyendo, comprobamos que a medida que descubrimos la enorme obra de María Zambrano percibimos cómo el pensamiento femenino de la filósofa española más importante de todos los tiempos se introduce en nosotros, es fácil sentirse como un personaje propio de uno de sus «delirios»: como si tuviésemos los pies atravesados por fíbulas, tal que el mismo Edipo, y no pudiéramos dar un paso. De este modo, nos instalamos en el «Verbo» de Zambrano dentro de ese espacio único que es la tragedia, y difícilmente salimos de una de sus cumbres, Antígona, que nos habla como una contemporánea.

Antígona ha sido reivindicada como la mujer insurgente ante el poder del Estado. A pesar de todo, esa rebeldía no sirve de modelo unívoco a seguir, entre otras cosas, porque terminó llevándola a la muerte. Quizá sea de todo esto de lo que hable Virginia Trueba en el prólogo a su edición de La tumba de Antígona donde interpreta «la conciencia de la necesidad de feminizar, simbólicamente el mundo, haciendo de lo femenino un valor de alcance universal» (Zambrano 1967: 98).

Pero mejor, lo que de verdad importa, sería decirlo con las palabras de Zambrano-Antígona, tomadas del prólogo al Delirio (Zambrano 2014: 302): «Antígona está enterrada viva en nosotros, en cada uno de nosotros». 


\section{BIBLIOGRAFÍA CITADA}

Agamben, Giorgio (1998) [1995]. Homo sacer. El poder soberano y la nuda vida; trad. Antonio Gimeno Cuspinera. Valencia: Pre-Textos.

Amorós, Celia (1985). Hacia una crítica de la razón patriarcal. Barcelona: Anthropos.

Bauman, Zygmunt (2004) [2000]. Modernidad líquida, trad. Mirta Rosenberg. Buenos Aires: Fondo de Cultura Económica.

Butler, Judith (2001) [2000]. El grito de Antígona, trad. Esther Oliver. Barcelona: El Roure Editorial.

Cioran, Emil M. (1992) [1989]. Ejercicio de admiración y otros textos. Ensayos y retratos, trad. Rafael Panizo. Barcelona: Tusquets.

Deleuze, Gilles y Félix Guattari (1994) [1976]. Rizoma, trad. José Pérez Vázquez y Umbelina Larraceta. México: Ediciones Coyocoán.

Derrida, Jacques (1986) [1967]. De la gramatología, trad. Óscar de Barco y Conrado Ceretti, revisión Ricardo Potschart. México: Siglo XXI.

Gray, John (2013). La vida de los animales. Sobre el progreso y otros mitos modernos, trad. José Antonio Pérez de Camino. Madrid: Sexto Piso.

Hegel, Georg Wilhelm Friedrich (1966) [1807]. Fenomenología del Espíritu, trad. Wenceslao Roces (basada en el texto de Johaunes Hoffmeister, de la Editorial Félix Meiner, Hamburgo). México: Fondo de Cultura Económica.

Maillard, María Luisa (1997). María Zambrano: La literatura como conocimiento y participación. Lleida: Edicions de la Universitat de Lleida.

Moreno Sanz, Jesús (ed.) (2004). La razón en la sombra. Antología crítica. María Zambrano. Madrid: Siruela.

Rabinovich, Diana S. (1995). La significación del falo. Buenos Aires: Ediciones Manantial.

Revilla Guzmán, Carmen (2005). Entre el alba y la aurora. Sobre la filosofía de María Zambrano. Barcelona: Icaria.

Sánchez Villaseñor, José (2007). Pensamiento y trayectoria de José Ortega y Gasset. México DF: Universidad Iberoamericana.

Santos Otero, Aurelio de (1985). Los Evangelios Apócrifos. Madrid: Biblioteca de autores cristianos.

Schaberg, Jane (2002). Resurrection of Mary Magdalene: Legends, Apocrypha and the Crhistian Testament. New York, London: Continuum.

Sófocles (2008) [429, 406, 443]. Edipo rey. Edipo en Colono. Antígona. Shere, Jimena (trad.). Buenos Aires: Editorial Colihue.

Steiner, George (1984). Antígones. New Haven and London: Yale University Press.

Steiner, George (2013). Antígonas, trad. Alberto L. Bixio. Barcelona: Gedisa.

Tommasi, Wanda (2002). Filósofos y mujeres, trad. Carolina Ballester Meseguer. Madrid: Narcea.

Valls Llobet, Carme (2006). Mujeres invisibles. Barcelona, Mondadori.

Zambrano, María (1967). La tumba de Antígona y otros textos sobre el personaje trágico. Madrid: Cátedra.

Zambrano, María (2002). Cartas de la Pièce. Correspondencia con Agustín Andreu, ed. Agustín Andreu. Valencia: Pre-Texos.

Zambrano, María (2006): Escritos sobre Ortega. Madrid: Editorial Trotta.

Zambrano, María (2014): Obras completas IV. Escritos autobiográficos. Delirios. Poemas (1928-1990). Delirio y destino (1952). Barcelona: Galaxia Gutenberg. 
Zambrano, María (2015): Obras completas I. Libros (1930-1939). Horizonte del liberalismo. Los intelectuales en el drama de España. Pensamiento y poesía en la vida española. Filosofía y poesía. Barcelona: Galaxia Gutenberg.

Žižek, Slavoj (2004) [1994]. Goza tu síntoma (Lacan dentro y fuera de Hollywood), trad. Horacio Pons. Buenos Aires: Nueva visión.

Fecha de recepción: 12 de febrero de 2016.

Fecha de aceptación: 26 de enero de 2017. 